\title{
Learning Needs Assessment of Postmenopausal Women in a Rural Community, Karnataka, India
}

\author{
Jacintha Veigas ${ }^{1}$ Rajgopal K. ${ }^{2}$ Christopher Sudhakar ${ }^{3}$ \\ 1 Department of Community Health Nursing, Nitte Usha Institute of \\ Nursing Sciences, Nitte (Deemed to be University), Mangaluru, \\ India \\ 2 Department of OBG, Yenepoya Deemed to be University, Mangaluru, \\ India \\ ${ }^{3}$ Department of Mental Health Nursing, Director Quality MAHE \\ Manipal, India \\ J Health Allied Sci ${ }^{\mathrm{NU}}$ 2022;12:407-411. \\ Address for correspondence Jacintha Veigas, MSc, PhD, Department \\ of Community Health Nursing, Nitte Usha Institute of Nursing \\ Sciences, Nitte (Deemed to be University), Mangaluru 575018, India \\ (e-mail: jacintha@nitte.edu.in).
}

\begin{abstract}
Keywords

- assessment

- educational

- postmenopause

- learning requirement

- midlife women

Introduction Every woman uniquely experiences menopause. The problems can be either well managed or prevented if a woman is well informed. Healthy women are productive and establish healthy families. It is important therefore to find out what a woman needs to learn about menopause.

Objective To determine the learning needs of the women at the postmenopausal period.

Materials and Methods The study adopted an exploratory approach using a crosssectional design. The setting was selected conveniently. The investigator took a simple random sampling technique. Demographic proforma and learning needs assessment opinionnaire were used to collect data.

Results Most of the subjects (28.8\%) were belonging to 51 to 55 years of age. The majority of the subjects (75\%) attained menopause between the age of 41 and 50 years. More than third-fourth of the subjects (77.5\%) were of a nuclear family. Eighty percent of the subjects were married. Around $68.8 \%$ had secondary education; $71.3 \%$ were housewives. Subjects had significant learning needs in the areas of "lifestyle modification" (mean \%= 44.42) and "sexual health" (mean \%=35.75). Eighty-one percent felt that they needed to give more importance to their children than their health. Thirty-nine subjects ranked "prevention of bone loss and joint pain" as their first preference of learning, 19 ranked "mental health" as their seventh preference; and 20 subjects ranked "sexual health" as their eighth preference of education.

Conclusion There is a need to train women on lifestyle modification and the promotion of sexual health during the postmenopausal period. They do need information on the enhancement of physical and mental health.
\end{abstract}

DOI https://doi.org/ $10.1055 / \mathrm{s}-0042-1742373$. ISSN 2582-4287. (c) 2022. Nitte (Deemed to be University). All rights reserved. This is an open access article published by Thieme under the terms of the Creative Commons Attribution-NonDerivative-NonCommercial-License, permitting copying and reproduction so long as the original work is given appropriate credit. Contents may not be used for commercial purposes, or adapted, remixed, transformed or built upon. (https://creativecommons.org/ licenses/by-nc-nd/4.0/)

Thieme Medical and Scientific Publishers Pvt. Ltd., A-12, 2nd Floor, Sector 2, Noida-201301 UP, India 


\section{Introduction}

Women experience complex health problems at midlife and thus have a lowered quality of life. They experience various menopausal symptoms. Improper lifestyle, psychological factors such as worry about losing their womanhood, attraction, and feeling of worthlessness affect their health. Living with a positive approach can help them lead a richer life. ${ }^{1}$ Menopause is a normal part of a woman's life. In developing countries, different stages of menopause comprise a half or a third of a woman's life. The various changes of menopause could cause stress and disability if not managed adequately.

It is observed worldwide that the cardiovascular disease (CVD) is one of the leading causes of death among the postmenopausal women. ${ }^{2}$ Vulvovaginal atrophy is a silent epidemic that affects up to 50 to $60 \%$ of postmenopausal women who are suffering in silence from this condition. ${ }^{3}$ From 45 to 54 years and from 55 to 64 years of age, the percentage of hypertensive men is similar to that of hypertensive women. After 65 years of age, BP levels increase faster in women than in men. ${ }^{4}$ Women lose $0.5 \%$ of bone density every year after the age of 50 years. Osteoporosis and fracture occur commonly in postmenopausal women, who experience a natural decline in endogenous estrogen. ${ }^{5}$ An increased risk of ovarian, breast, and uterine cancers have been observed in women who experience menopause after the age of 55 years. ${ }^{6}$

The studies on the impact of information on healthy behaviors and stress management have shown enhanced women's knowledge, healthy habits, and sexual interest. ${ }^{7}$ People have the misconception that women who engage in sexual intercourse after menopause are prone to lose their health. Even men avoid having sex with menopausal woman. ${ }^{8}$ India, as a developing country, rapidly grows in every sphere of life. As a result, health and life expectancy, especially among women, has improved. They spend one-third of their life as menopausal women. ${ }^{9}$ The quality of living, inclusive of personal and work experience, is affected due to the vasomotor symptoms faced by menopausal women. ${ }^{10}$ Women tend to disclose that these symptoms are more challenging to manage in the workplace due to embarrassment and concern about others reactions. At the same time, specific working environments may worsen the experience of menopausal challenges, which in turn affects the work outcome. The provision of adequate support and awareness to women with problems will retain them in the labor force. Managers should know the learning needs of menopausal women at the transition period so that appropriate educational intervention can be undertaken to promote health and productivity at the work place. ${ }^{11}$

Every woman uniquely experiences menopause. It is ideal to find out what a woman needs to learn about menopause, to manage or prevent their health problems. Hence, the investigator initiated this work to determine the learning needs of the postmenopausal women.

\section{Materials and Methods}

The constructed tool for assessing the learning needs of postmenopausal women was administered to 10 postmeno- pausal women to find out any difficulty in understanding or completing it. The investigator observed no problems. The reliability of the learning needs assessment scale was established using Cronbach's alpha $(\alpha=0.822)$.

\section{Ethical Consideration}

The investigator obtained ethical clearance from the ethics committee of the institution. Received permission from the District Health Officer, Mangaluru, to conduct the study in the villages covered by the Primary Health Centers. These are the rural areas of Mangaluru city. Investigator obtained permission from the director of nongovernmental organization (NGO) functioning in that area to conduct the study. The investigator met the subjects and explained the purpose, procedure, benefits, duration of the research, and their role in the study. Investigator obtained informed consent and assured confidentiality of the information.

\section{Methodology}

In this study, exploratory approach with a cross-sectional design was used. Out of the six villages covered by the NGO, the investigator conveniently selected one village to conduct the learning needs assessment. The frame of reference for the postmenopausal women was available in that village as there was another project going on for the women of same age group in that center. The selected village had one center where the women beneficiaries were expected to attend monthly meeting without fail. The investigator conducted the learning needs assessment, during the monthly meeting by selecting 80 subjects using simple random sampling. The sample size was calculated based on the findings of the previous study. The investigator used tool I, composed of nine items for collecting the demographic data. The researcher used tool II, the learning needs assessment opinionnaire, with 20 items in Part A, to identify the learning requirement. It had agree and disagree options with a remark column. The investigator scored one for every correct opinion expressed of a positive item, and zero to wrong opinion. The researcher used reverse scoring to negative items. This tool had maximum 20 scores. The Part B had three items, namely, positive body image, self-reported health problems, and self-reported lifestyle. The investigator did not score these items. The Part $\mathrm{C}$ had one item on ranking the areas according to the preference of learning. The researcher did not score these items. The investigator translated the tools to Kannada and then back to English. The subjects took around 15 to 20 minutes to complete the tool.

\section{Results}

Almost half $(48.8 \%)$ of the number of subjects had two children. Nearly half (46.3\%) of the number of subjects had a monthly income more than Rs. 5,000.

Twenty-eight percent of the subjects were belonging to 51 to 55 years of age. Three-fourth of the subjects (75\%) attained menopause between the age of 41 and 50 years. More than three-fourth $(77.5 \%)$ of the subjects belonged to nuclear family. Majority of the subjects (80\%) were married. Nearly half $(48.8 \%)$ of the number of subjects had two children. 
Table 1 Areawise distribution of mean, standard deviation, and mean percentage of the subjects selected for learning needs assessment, $n=80$

\begin{tabular}{|l|l|l|l|l|l|}
\hline Area & Maximum score & Range & Mean (SD) & Mean \% & Inference \\
\hline Lifestyle modification & 7 & $1-6$ & $3.11(1.565)$ & 44.42 & High \\
\hline Health checkup & 4 & $1-4$ & $2.52(0.753)$ & 63.00 & Moderate \\
\hline Sexual health & 4 & $0-4$ & $1.43(0.311)$ & 35.75 & High \\
\hline Physical and mental health & 5 & $1-5$ & $2.98(0.017)$ & 59.60 & Moderate \\
\hline Overall need score & 20 & $5-16$ & $10.06(2.270)$ & 50.00 & High \\
\hline
\end{tabular}

Abbreviation: SD, standard deviation.

Majority (93.8\%) were nonvegetarians. Majority (68.8\%) had secondary education; almost three-fourth $(71.3 \%)$ were housewives. Nearly half $(46.3 \%)$ of the number of subjects had a monthly income more than Rs. 5,000. Subjects had high learning needs in the areas of "lifestyle modification" (mean \%=44.42) and "sexual health" (mean \%=35.75). Overall learning needs was high (mean $\%=50.00$ ) (-Table 1).

\section{Itemwise Analysis of Learning Needs}

Less than $50 \%$ expressed that they had no time to do exercise daily. Sixty-five percent felt lazy to do exercises. More than 50\% of the number of subjects ( $60 \%$ each) expressed fear to go for health checkup and difficulty in consuming fruits and vegetables every day because of the high cost involved. More than a quarter (38.8\%) expressed that they had family support to go for health checkup/screening. Only $38.8 \%$ felt that sexual life should be given importance at this stage of life. Less than $50 \%$ of the number of subjects ( $42.5 \%$ ) felt sexual relation is essential for a better relationship between the couple. Majority (81.3\%) felt that they needed to give more importance to their children than their own health. More than half of the number of subjects (63.8\%) expressed that in spite of having various responsibilities, they can pay attention to their health. Ninety-five percent wished to be healthy and not to be burden to their family members. Majority (90\%) felt that they could be still productive and useful in the society.

\section{Perceived Body Image}

The data presented in - Fig. 1 show that majority of subjects (70\%) had positive body image. Hence, there are more opportunities to strengthen their motivational ability and to empower them.

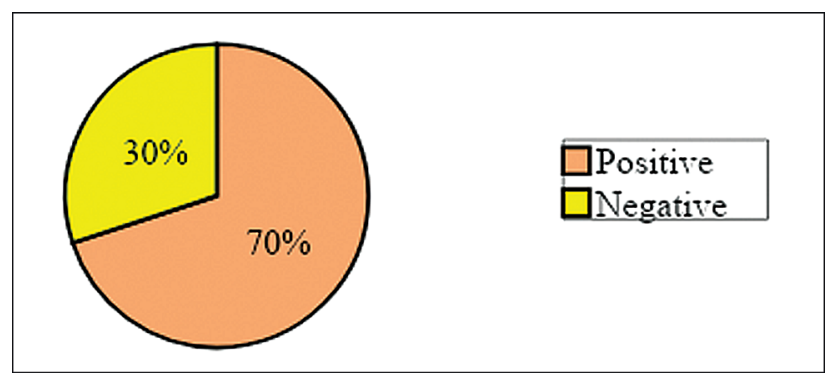

Fig. 1 Perceived body image.

\section{Self-reported Health Problems}

The data presented in - Fig. 2 reveal that $40 \%$ of the subjects had sleeplessness, 23\% had urinary incontinence, and $28 \%$ had low sexual interest.

\section{Self-reported Health Practices}

The data presented in - Fig. 3 reveal that 65\% consumed fruits and vegetables daily. Only $11 \%$ went for regular health checkup.

The data presented in - Table 2 show that 39 subjects ranked "prevention of bone loss and joint pain" as their first preference; 19 ranked "mental health" as their seventh preference; and 20 subjects rated "sexual health" as their eighth preference. "Weight control," "cardiac health," and "prevention of cancer, including breast self-examination" were the priorities of 35,33 , and 31 subjects, respectively.

\section{Discussion}

The findings of the present study are compared with other studies to translate the available data into information.

The majority of the subjects (75\%) attained menopause between the age of 41 and 50 years. Around 68.8\% had secondary education. Almost three-fourth were housewives. Seventy percent had a positive body image. In a study conducted in Gujarat to find out the health problems among postmenopausal women, the majority of the subjects (73.5\%) were housewives. Most of them had studied up to class IV or V. ${ }^{12}$ Another study conducted in Maharashtra on orthopaedic morbidities among postmenopausal women showed that most of them were in the age group of 55 to 65 years. Around $68.6 \%$ were illiterate. ${ }^{13}$ The investigator in the present study strongly feels that the villages selected for the study, though in the outskirts of Mangaluru city, are developing and have an urban touch. That may be the reason for the high percentage (68.8\%) of the subjects to have secondary education.

In the present study, subjects had a high learning requirement in the areas of "lifestyle modification (mean \% = 44.42) and "sexual health" (mean \%=35.75\%). The overall learning needs was high (mean $\%=50$ ). The investigator observed a great learning needs in a study conducted on the prevalence of conventional CVD risk factors in postmenopausal women. Only $3 \%$ of the subjects knew of the importance of lifestyle modification, and $9 \%$ were aware of menopause. ${ }^{14}$ The above information clearly says that women's learning needs are high. 


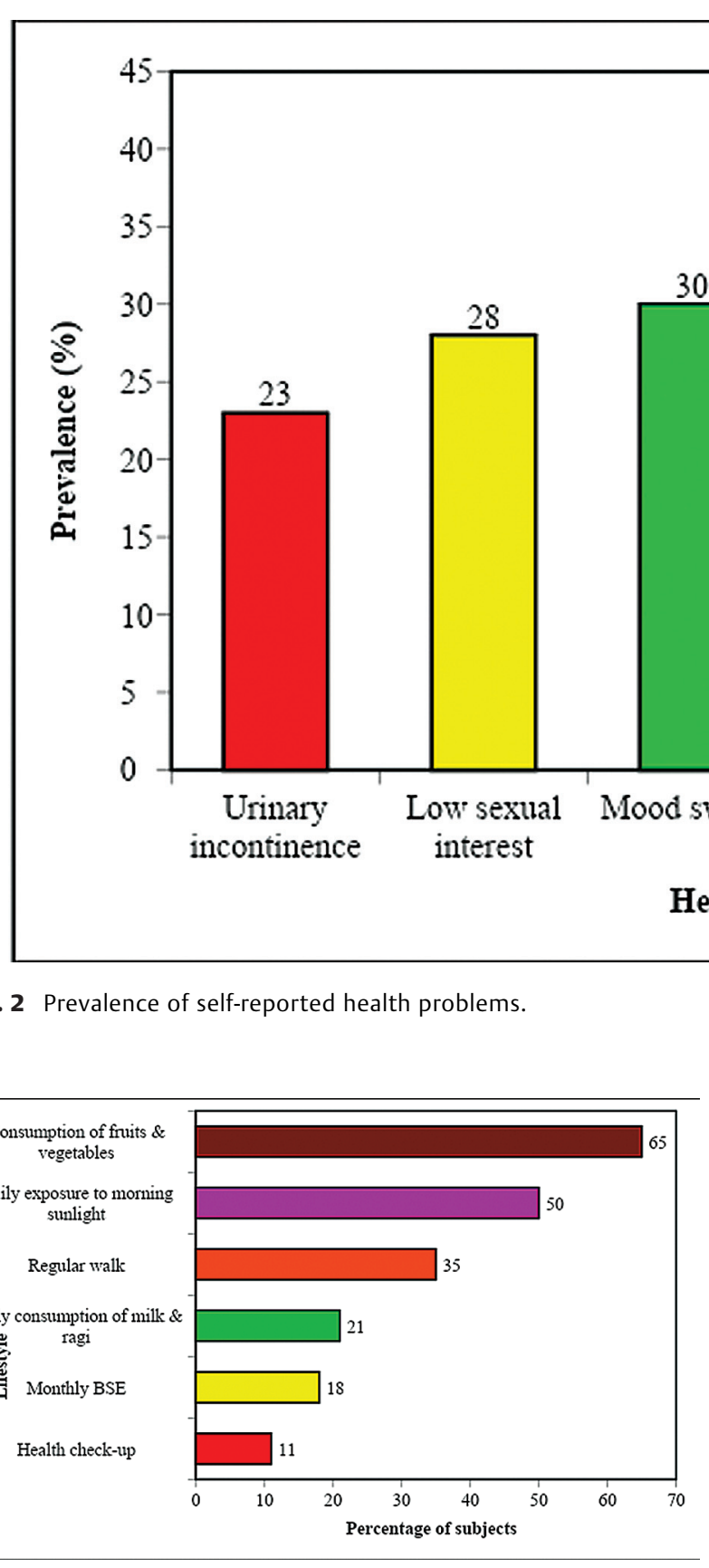

Fig. 3 Self-reported health practices. BSE, breast self-examination.

In the present study, $40 \%$ of the subjects reported sleeplessness, 33\% weight gain, 23\% urinary incontinence, and 30\% hot flushes. A study conducted at Mangaluru, Karnataka also revealed a still higher burden of problems, namely, $62 \%$ had hot flushes, $46 \%$ developed a urinary infection, $58 \%$ had insomnia, and $48 \%$ weight gain. ${ }^{15}$ Another study on health problems among rural postmenopausal women also revealed insomnia (57.1\%) and hot flushes (40.1\%). ${ }^{12} \mathrm{~A}$ population-based survey on menopausal symptoms revealed issues such as urinary symptoms (11.7\%). The majority of the women $(88.1 \%)$ reported one or more postmenopausal symptoms. ${ }^{16}$ A study on postmenopausal symptoms in Kerala also revealed that $31.8 \%$ had genital problems (itching, vaginal dryness). Fifty-three percent had musculoskeletal difficulties. ${ }^{17}$ The investigator strongly feels that postmenopausal women have one or other health problems.

In the present study, only $38.8 \%$ felt the importance of sexual life. But $42.5 \%$ felt sexual relation is essential for a better relationship between the couple. Many women did not reply to items related to their sexual life. In a study on social dimensions of menopause, $23 \%$ felt that sexual life ends with the onset of menopause. Sixteen percent had reported that their husbands had become disinterested after menopause. About $11 \%$ were anxious about the loss of womanhood. Fifty-nine percent of the postmenopausal women expressed that they had lost sexual desire. ${ }^{17}$ In a study on menopausal symptoms in rural Kerala, $31.8 \%$ of women experienced sexual problems such as decreased libido and dyspareunia. ${ }^{8}$

The investigator in the present study observed that $81.3 \%$ had expressed that at the postmenopausal stage, they would give more importance to their children than their health. Women may not be showing much interest in learning about menopausal health promotion, but they are only bothered about their family and children. Sixty-three percent of the subjects expressed this view. The investigator feels that sexual issue is less taken care among postmenopausal women. The subjects had also suggested the investigator to give an awareness program for their husbands. It thus clarifies that the couple does not frankly discuss the sexual difficulties. It is, therefore, essential to create awareness among men regarding menopause. 
Table 2 Learning needs of the subjects according to their preference of learning, $n=80$

\begin{tabular}{|c|c|c|c|c|c|c|c|c|c|}
\hline \multirow[t]{2}{*}{ Area } & \multicolumn{9}{|c|}{ Order of preference (frequency) } \\
\hline & 1 & 2 & 3 & 4 & 5 & 6 & 7 & 8 & 9 \\
\hline Prevention of bone loss and joint pain & 39 & 4 & 5 & 3 & 6 & 3 & 8 & 5 & 8 \\
\hline Weight control & 35 & 12 & 6 & 9 & 13 & 1 & 3 & 1 & 0 \\
\hline Cardiac health & 33 & 6 & 8 & 8 & 2 & 5 & 5 & 4 & 9 \\
\hline Prevention of cancer including BSE & 31 & 15 & 5 & 9 & 2 & 10 & 4 & 0 & 4 \\
\hline Exercise including exercise to strengthen the bladder muscles (Kegel) & 27 & 16 & 6 & 7 & 9 & 5 & 5 & 5 & 0 \\
\hline Healthy diet & 16 & 16 & 16 & 4 & 9 & 9 & 4 & 3 & 3 \\
\hline Lifestyle modification & 15 & 3 & 7 & 12 & 12 & 10 & 7 & 9 & 5 \\
\hline Sexual health & 15 & 1 & 6 & 6 & 5 & 6 & 5 & 20 & 16 \\
\hline Mental health & 14 & 5 & 5 & 6 & 4 & 11 & 19 & 12 & 4 \\
\hline
\end{tabular}

Abbreviation: BSE, breast self-examination.

\section{Limitations of the Study}

The study is limited to the women willing to participate, had natural menopause, who were not on hormone replacement therapy, who had experienced 12 consecutive months of amenorrhea, and belonged to the age equal to or younger than 60 years.

\section{Conclusion}

The women feel mental and sexual health are not important in promoting their health during postmenopause. They spend more time and energy in taking care of their children and family. The majority of the women have positive body image; therefore, it would be easier to motivate them to promote their health so that they would remain fruitful.

Source(s) of Support in the Form of Grant

Self-funded.

Note

The manuscript has not been published previously and has been read and approved by all authors.

Conflict of Interest

None declared.

\section{Acknowledgment}

The authors thank wholeheartedly the participants for their cooperation during the study.

\section{References}

1 Kwak EK, Park HS, Kang NM. Menopausal knowledge, attitude, symptoms and management among midlife employed women. J Menopausal Med 2014;20(03):118-125

2 Pardhe BD, Ghimire S, Shakya J, et al. Elevated cardiovascular risks among postmenopausal women: a community based case control study from Nepal. Biochem Res Int 2017;2017:3824903

3 Naumova I, Castelo-Branco C. Current treatment options for postmenopausal vaginal atrophy. Int J Womens Health 2018;10:387-395
4 Cannoletta M, Cagnacci A. Modification of blood pressure in postmenopausal women: role of hormone replacement therapy. Int J Womens Health 2014;6:745-757

5 Yu J, Cao G, Yuan S, Luo C, Yu J, Cai M. Probiotic supplements and bone health in postmenopausal women: a meta-analysis of randomised controlled trials. BMJ Open 2021;11(03):e041393

6 Surakasula A, Nagarjunapu GC, Raghavaiah KV. A comparative study of pre- and post-menopausal breast cancer: risk factors, presentation, characteristics and management. J Res Pharm Pract 2014;3(01):12-18

7 Yazdkhasti M, Simbar M, Abdi F. Empowerment and coping strategies in menopause women: a review. Iran Red Crescent Med J 2015;17(03):e18944

8 Borker SA, Venugopalan PP, Bhat SN. Study of menopausal symptoms, and perceptions about menopause among women at a rural community in Kerala. J Midlife Health 2013;4(03):182-187

9 Pathak V, Ahirwar N, Ghate S. Study to assess knowledge, attitude and practice regarding menopause among women attending outdoor in tertiary care centre. Int J Reprod Contracept Obstet Gynecol 2017;6(05):1848-1853

10 Claire H, Eleanor T, Amanda G, Myra S. Hunter Work outcomes in midlife women: the impact of menopause, work stress and working environment. Womens Midlife Health 2018;4(03):2-8

11 Jafari M, Seifi B, Heidari M. Risk assessment: factors contributing to discomfort for menopausal women in workplace. J Menopausal Med 2017;23(02):85-90

12 Christian DS, Kathod MM, Bhavsar BS. A clinico-epidemiological study on health problems of postmenopausal women in rural area of Vadodara district, Gujarat. Indian J Med Res 2012;2(04):478-480

13 Avachat SS, Desphande SB, Zambare MB, Phalke DB. Study of orthopaedic morbidities among postmenopausal women in rural area of western Maharashtra, India. Indian J Clin Pract 2013;24 (06):574-577

14 Tandon VR, Mahajan A, Sharma S, Sharma A. Prevalence of conventional cardiovascular disease risk factors (CVRFS) in postmenopausal women. J Midlife Health 2010;1(01):26-29

15 Nayak BK. A study on women aged 40-50 years on the problems caused by menopause at Mangalore, D. K. district. HealthAction 2008; $\cdots: 18-21$

16 Dutta R, D'Cruze L, Anuradha R, Rao S, Rashmi MR. A population -based study on the menopausal symptoms in a rural area of Tamil Nadu, India. J Clin Diagn Res 2012;6(04):597-600

17 Khan S, Shukla MK, Priya N, Ansari AM. Health seeking behavior among postmenopausal women: KAP. Int J Community Med Public Health 2016;3(07):1777-1782 